\title{
Predictive factors of quality of life among medical students: results from a multicentric study
}

\author{
Alice de Queiroz Constantino Miguel ${ }^{1,3^{*}}{ }^{\mathbb{D}}$, Patricia Tempski ${ }^{1}$, Renata Kobayasi ${ }^{1}$, Fernanda B. Mayer ${ }^{4}$ \\ and Milton A. Martins ${ }^{1,2}$
}

\begin{abstract}
Background: Medical students have a worse perception of Quality of Life (QoL) and a high prevalence of psychosocial suffering when compared to the general population. The objective of this study was to investigate associated factors with Quality of Life of Brazilian medical students from an exploratory analysis in a cross-sectional study described in accordance with the STROBE (Strengthening the Reporting of Observational studies in Epidemiology) guidelines.

Methods: This is a cross-sectional and multicenter study with national sample randomized by sex and year of the course. Data were collected between August 2011 and August 2012, using an electronic platform (VERAS platform). Our outcomes included: personal quality of life (QoLp) and quality of life related to medical course activities (QoLmc), both measured using a score ranging from 0 (worst) to 10 (best). Variables as predictors: the World Health Organization Quality of Life Assessment abbreviated version (WHOQOL-BREF); VERAS-Q (a questionnaire created to evaluate the QoL of students in health professions); Epworth Sleepiness Scale (ESS), Pittsburgh Sleep Quality Index (PSQI), Beck Depression Inventory (BDI), State-Trait Anxiety Inventory (STAI), Maslach Burnout Inventory (MBI), Resilience Scale (RS-14), Interpersonal Reactivity Multidimensional Scale (IRMS) and Dundee Ready Education Environment Measure (DREEM).

Results: Our sample is comprised of 1350 (81.8\%) medical students. When comparing predictors and both quality of life outcome measures, we found a negative correlation between QoL and the BDI, PSQI and ESS scores. Through a multiple linear regression mode we identified the median of significant predictors to higher QoL. We then run a tree regression model that demonstrated that the VERAS-Q_- physical health domain (a domain assessing self-care, selfperception of health, sleep, leisure, physical activity and appearance) was the most important factor predicting QoL. Students with a VERAS-Q-physical health score $\geq 60.9$ and a VERAS-Q-time management (address the management of the student's time, free time and whether he can dedicate himself to other activities besides the course) score $\geq 55.7$ presented the best QoLmc (score: 8.08-9.63\%). Students with a VERAS-Q-physical health score $\geq 79.7$ presented the highest QoLp (score 8.93-8.74\%).
\end{abstract}

Conclusion: Physical symptoms, self-perception of health and self-care assessed by the VERAS-Q physical domain had association with both final outcomes. Time management seems to have a protective role for better Quality of

\footnotetext{
*Correspondence: aliceqcmiguel@gmail.com

${ }^{1}$ Centro de Desenvolvimento de Educação Médica, Faculdade de

Medicina da Universidade de Sao Paulo, Av. Dr. Arnaldo 455 sala 1210, Sao

Paulo, SP 01246-903, Brazil

Full list of author information is available at the end of the article
}

(C) The Author(s) 2021. Open Access This article is licensed under a Creative Commons Attribution 4.0 International License, which permits use, sharing, adaptation, distribution and reproduction in any medium or format, as long as you give appropriate credit to the original author(s) and the source, provide a link to the Creative Commons licence, and indicate if changes were made. The images or other third party material in this article are included in the article's Creative Commons licence, unless indicated otherwise in a credit line to the material. If material is not included in the article's Creative Commons licence and your intended use is not permitted by statutory regulation or exceeds the permitted use, you will need to obtain permission directly from the copyright holder. To view a copy of this licence, visit http://creativecommons.org/licenses/by/4.0/. The Creative Commons Public Domain Dedication waiver (http://creativeco mmons.org/publicdomain/zero/1.0/) applies to the data made available in this article, unless otherwise stated in a credit line to the data. 
Life. These variables should be taken in consideration when designing interventions to improve Quality of Life among medical students.

Keywords: Quality of life, Students, Medical, Time management, Predictive factors, Education, Medical, Multicenter study

\section{Background}

The stressful nature of medical education can affect medical student's physical and mental health, and thus, their quality of life [1-7]. Medical students have worse perception of their Quality of Life (QoL) than the general population, even when matched by gender and age [8-12]. Worse perception of QoL among medical students was also observed comparing with other university students. Bittencourt and Paro [11] assessed the perception of QoL of students in Medicine, Nursing, Pharmacy and Speech Therapy courses. They observed that medical students had lower QoL scores compared to other students. Lack of free time and fatigue were considered the main reasons this difference [11].

In addition, they medical students present a high prevalence and intensity of psychosocial distress and mental disorders, such as depression, anxiety, burnout syndrome, suicidal ideation and attempt, pathological sleep disorders, alcohol and drug use and abuse $[3,4$, 13-27]. This higher morbidity for mental disorders has a negative impact on academic and professional performance of these students [4, 28-32]

Humanistic theory from Carl Rogers states that people are always in the process of changing and growing. The ability to adapt, learn and change plays a vital role in this theory. Quality of life or happiness is a process, not a state of being. Using this framework, it is important to elucidate the factors that help and/or oppose this process in the life of medical students [33, 34].

Despite a growing number of studies on this topic, it is still not clear what are the risk factors associated to worse QoL as well as the protective factors. Few previous studies have globally investigated these factors. Notwithstanding, the identification of modifiable risk factors are relevant for the design of preventive interventions at an early stage in vulnerable individuals. Quality of life is a multidimensional construct with many protective and risk factors. In medical students it has been suggested that time management, physical activity, resilience and empathy can be protective and depression, anxiety, sleep deprivation and burnout may act in the opposite direction.

The aim of this research was to identify the factors that positively and negatively impact the quality of life of medical students. To accomplish it we made a multiple exploratory analysis to evaluate individual and medical curriculum related factors contributing toward higher and lower QoL levels among this group of individuals. For this analysis, we used data of a multicentric Brazilian study aimed to evaluate quality of life of medical students (VERAS an acronym that means Life of Students and Residents of Health Professions). We previously published data from this study showing associations between QoL and burnout, empathy, educational environment, leisure-time physical activity, resilience, anxiety and depression symptoms [35-40]. In the present study, we evaluate the influence of all these factors in QoL in general and QoL related to medical course QoL.

\section{Methods}

This is a cross-sectional study to evaluate factors contributing toward Quality of Life among medical students. This study is described in accordance with the STROBE (Strengthening the Reporting of Observational studies in Epidemiology) guidelines [41].

The Institutional Review Board of the School of Medicine of the University of São Paulo (CEP-FMUSP number $181 / 11$ ), as well as the institutional review boards of all other participating medical schools approved the study, with all participants providing informed consent before the implementation of any study protocol.

We conducted this investigation as part of a multicenter study involving 22 Brazilian medical schools (the VERAS study, translated to English as 'Students' and Residents' life in health professions"). Detailed description of this study was previously published $[2,36-40$, 42]. Schools participating in the study were from all regions of Brazil, and with a diverse legal status and location (13 public and 9 private); 13 in state capital cities and 9 in other cities). All medical schools included (Universidade Federal do Rio de Janeiro, Universidade Federal de Ciências da Saúde de Porto Alegre, Universidade Estadual do Piaú, Faculdade de Medicina de Petrópolis, Faculdade de Ciências Médicas da Paraíba, Pontifícia Universidade Católica de São Paulo, Universidade Federal do Ceará, Universidade Federal de Goiás, Universidade Federal de Mato Grosso do Sul, Escola Baiana de Medicina e Saúde Pública, Faculdade de Medicina de Marília, Faculdade de Medicina de São José do Rio Preto, Faculdade de Ciências Médicas da Paraíba, Faculdade Evangélica do Paraná, Faculdade de Medicina do ABC, Fundação Universidade Federal 
de Rondônia, Pontifícia Universidade Católica do Rio Grande do Sul, Universidade Federal do Tocantins, Universidade Federal de Uberlândia, Universidade Estadual Paulista Júlio de Mesquita Filho, Centro Universitário Serra dos Órgãos, Universidade de Fortaleza and Universidade de Passo Fundo[43]) approved the study.

Students were stratified into clusters by gender and program year, using a computer-generated list of random numbers. Medical students included in the study received a link from both institutional and personal emails to access an electronic survey platform designed specifically for this project. The first page of the survey was the written informed consent, the student could only continue if he/she read and agreed to participate in the study. Apart from data collected through formal, validated instruments (described below), we also collected socio-demographic data: age, sex, location and type of medical school (public or private), year of training education, information on financial support and housing, heigh and weight. Students were asked to complete the survey within 10 days. After completing the survey, students received automatic feedback on their scores for each domain of each questionnaire along with information about its interpretation. There were psychologists in the research group, so students could contact any of the coordinating researchers for guidance or emotional support throughout the study. Data were collected between August 2011 and August 2012.

\section{Participants}

A total of 153 Brazilian medical schools were considered for inclusion in our study. We only included medical schools with at least one class in the process of graduation, bringing the total target population to approximately 86,000 medical students across all six years of training. We defined our sample size $(n=1152)$ to achieve an effect size of 0.165 comparing two groups with the same size, also assuming a statistical power of $80 \%$ and a 0.05 significance level. We later increased the sample to 1650 students to account for a 30\% loss of participants. We then randomly selected at least 60 students from each of 22 medical schools. Next, we stratified all participants into clusters by gender and program year, i.e., five males and five females per each of the six program years, using a computer-generated list of random numbers. We excluded students who have not answer $100 \%$ of the questionnaires. To avoid sampling bias due to a low percentage of responses, we defined a minimum response rate of $60 \%$ in each medical school to include the responses in the final analysis, according to the recommendation of Huston [44].

\section{Outcomes}

Our outcomes of interest included: (a) personal quality of life (QoLp) measured using a self-reported analog scale with a score ranging from 0 (worst) to 10 (best), and (b) quality of life (QoLmc) related to medical course activities measured using a score ranging from 0 (worst) to 10 (best).

\section{Predictors}

We selected the following scales and instruments to investigate predictive factors:

World Health Organization Quality of Life Assessment abbreviated version (WHOQOL-BREF) is a brief version of the WHOQOL 100 and consists of 26 items, clustered into the following four domains: physical health, psychological health, social relationships and environment. Higher scores represent better QoL. This questionnaire was translated and validated to Brazilian Portuguese [45, 46]. The Cronbach's alpha for each domain was 0.66 for social relationships, 0.73 for environment, 0.75 for physical health and 0.79 for psychological health.

$V E R A S-Q$ is a questionnaire created to evaluate the QoL of students in health professions (Additional file 1). It consists of 45 items with a 5-point Likert scale divided into four domains (time management, psychological, physical health, and learning environment) and a global score. The score ranges from 0 (worst quality of life) to 100 (best quality of life) [47]. The Cronbach's alpha for each domain was 0.77 learning environment, 0.79 for physical health, 0.82 for both psychological and time management and 0.91 for global score.

Epworth Sleepiness Scale (ESS) is a self-reported questionnaire evaluating the likelihood of falling asleep in eight situations involving daily activities, on a scale of $0-3$ (where $0=$ would never doze and $3=$ high chances of dozing). The overall score ranges from 0 to 24 with higher scores representing a person's daytime sleepiness. A version has been translated and validated for Brazilian Portuguese $[48,49]$. The Cronbach's alpha for this questionnaire was 0.74 .

Pittsburgh Sleep Quality Index (PSQI) measures selfreported sleep quality and disturbance over the past one month. The PSQI is composed of 19 items, which are combined into seven constructs that are summarized into a global score ranging from 0 to 21 , where the highest score indicates worst sleep quality. This questionnaire was translated and validated to Brazilian Portuguese [50, 51]. The Cronbach's alpha for this questionnaire was 0.65 .

Beck Depression Inventory (BDI), is a 21-item, selfreported measure that measures characteristic attitudes and symptoms of depression. Responses are scored on a 
4-point scale, ranging from 0 to 3 , and total scores can range from 0 to 63 . The higher the score, the greater the symptom intensity. This questionnaire was translated and validated to Brazilian Portuguese [52, 53]. The Cronbach's alpha for this questionnaire was 0.87 .

Resilience Scale (RS-14) measures the level of individual resilience, a person's ability to cope with problems and withstand pressure in adverse situations without suffering physical, psychological, or social harm. It involves adaptive skills, flexibility, interaction, overcoming and resignification of lived experiences. The scale consists of 14-items and was translated and validated to Brazilian Portuguese [54, 55]. The Cronbach's alpha for this questionnaire was 0.87 .

State-Trait Anxiety Inventory (STAI) is a self-reported questionnaire consisting of 40 items used to measure the presence and severity of anxiety symptoms. This scale is composed of two distinct subscales: the state anxiety scale evaluates current behavior while the trait anxiety scale evaluates personality. This questionnaire was translated and validated to Brazilian Portuguese [56-58]. The Cronbach's alpha for this questionnaire was 0.92 and 0.93, respectively for Trait and State anxiety.

Interpersonal Reactivity Multidimensional Scale (IRMS) evaluates empathy and its associated factors. It consists of 21 statements describing personal characteristics and following three main domains including empathic, emotional, and behavioral components. Medical students' empathy was measured using three subscales of the validated version of the EMRI for Brazilian-Portuguese $[59,60]$. The Cronbach's alpha for each domain was 0.61 for emotional, 0.73 for empathic and 0.77 for behavioral.

Maslach Burnout Inventory (MBI) is a burnout assessment instrument consisting of 22 items divided into three domains: emotional exhaustion, depersonalization, and personal accomplishment. Each domain is scored on a seven-point Likert scale, with values from 0 (never) to 6 (every day). Burnout intensity is determined by the summing the scores of questions pertaining to each domain. Higher scores correspond to a higher degree of burnout. This questionnaire was translated and validated to Brazilian Portuguese $[61,62]$. The Cronbach's alpha for each domain was 0.68 for depersonalization, 0.81 for personal accomplishment and 0.85 for emotional exhaustion.

Dundee Ready Education Environment Measure (DREEM) contains 50 statements relating to the educational environment, scored on a five-point Likert scale $(0=$ strongly disagree and $4=$ strongly agrees), some of which are inverted. Higher scores indicate a positive evaluation. The DREEM has a maximum score of 200, which represents an ideal educational environment. The subscales are as follows: Students' perceptions of Learning
(SPL); Students' perceptions of Teachers (SPT; Students' Academic Self Perception (SASP); Students' perceptions of Atmosphere (SPA); Students' social self-perceptions (SSSP). This questionnaire was translated and validated to Brazilian Portuguese $[63,64]$. The Cronbach's alpha for each domain was 0.65 for SSSP, 0.71 for SASP, 0.82 for SPL, 0.83 for SPA, 0.84 for SPT and 0.94 for global score.

\section{Potential confounders}

We selected potential confounders using a combination of clinical judgment and evidence from the literature, as these joint criteria have been demonstrated to perform better than the isolated selection of isolated clinical or evidence-based criteria [65]. We selected age, gender, body mass index, and school levels as potential confounders [66].

\section{Statistical analysis}

We started with a descriptive and visual exploratory analysis of all variables to evaluate their frequency, percentage and near-zero variance for categorical variables, distribution for numeric variables, and their corresponding missing value patterns [67]. Comparisons for the exploratory analysis were conducted through analysis of variance ( $t$-tests being a category of analysis of variance) and Chi-square tests (Fisher exact test when any cell presented a frequency below 5).

Our strategy to evaluate predictors and their relationship with study outcomes (personal and related to medical course QoL) made use of a series of generalized linear models with a Gaussian family, i.e., Multiple Linear Regression Models (MLRM). The regression models were adjusted for age, gender, body mass index, and school levels. We used $\mathrm{p}$ for trend to measure the impact of individual numeric predictors on each of the QoL outcomes. In order to calculate predicted mean values for the outcome rather than simply obtaining less clinically interpretable measures of correlation, we categorized predictors at their median value (for example, median of Resilience Scale scores of 81, global DREEM score of 120). Results are reported as predicted means with $95 \%$ confidence intervals, with results being interpreted as significant when the confidence intervals do not overlap between different estimates along with $\mathrm{p}$ for trend $<0.001$ [68].

We also used Regression Trees Model (RTM) with the same set of previously described outcomes and predictors. Regression trees complement the use of machine learning models as they represent the best cut-points for predictor values in the context of a given outcome after previous predictors have been taken into account. In order to avoid overfitting, we used a cost-complexity pruning strategy using the weakest link pruning strategy 
by successively collapsing the internal node that produces the smallest per-node increase in the cost complexity criterion [69]. When overfitting is detected, those nodes were removed. Otherwise, they were left intact. We have also provided a graphical representation of each model.

All analyses were performed using the $\mathrm{R}$ language with packages ggplot2 and rmarkdown; using the SPSS software version 22;

\section{Results}

\section{Descriptive and visual exploratory analysis}

Table 1 displays the description of the overall study sample. Our sample is comprised of 1350 medical students, most of them being females (52.9\%), the sample having a mean age of 22.8 years and an average Body Mass Index of $23.2 \pm 3.5 \mathrm{~kg} / \mathrm{m}^{2}$.

\section{Univariate analysis}

When evaluating the association between study outcomes, personal QoL and QoL related to medical course presented a positive correlation $(0.566 ; p<0.001)$ (Fig. 1$)$.

When comparing predictors and both quality of life outcome measures, we found a negative correlation between QoL related to medical course and the Beck Depression Inventory (correlation $=-0.397, p<0.001$ ), Pittsburgh Sleep Quality Index $(0.345, p<0.001)$ and Epworth Sleepiness Scale scores $(-0.211, p<0.001)$. These finding indicate that an increased quality of life is associated with lower depression symptoms, better sleep quality and lower levels of daytime sleepiness. Correlation with the same direction was observed between personal QoL and Beck Depression Inventory $(-0.339$, $p<0.001)$, Pittsburgh Sleep Quality Index $(-0.276$, $p<0.001)$ and the Epworth Sleepiness Scale scores $(-0.092, p<0.001)$.

\section{Multiple linear regression model (MLRM)}

Table 2 shows the association between predictors and both QoL related to medical course and personal QoL, evaluated through a multiple linear regression model and adjusted for age and Body Index Mass.

When comparing predictors with both QoL related to medical course and personal QoL, significant predictors of higher QoL included: Beck Depression Inventory (above and below a median of 8 ) (6.96 vs. 6.02 for QoL medical course, 8.17 vs. 7.53 for QoL personal), global Pittsburgh Sleep Quality Index at median of 6 (6.93 vs. $6.07,8.12$ vs. 7.60 ), Epworth Sleepiness Scale at median 10 (6.84 vs. 6.14, 7.98 vs. 7.73), WHOQOL-BREF domains scores including environment at median of 65.6 (6.04 vs. $7.14,7.49$ vs. 8.36 ), social relations at median of 66.7 (6.22 vs. $6.94,7.61$ vs. 8.23 ), psychological at median of 62.5 (5.98 vs. $7.13,7.48$ vs. 8.30 ), and physical health
Table 1 Sample characteristics

\begin{tabular}{|c|c|}
\hline Variable & $\begin{array}{l}\text { Total (SD) } \\
1350\end{array}$ \\
\hline Age (years) & $22.8( \pm 3.01)$ \\
\hline $\mathrm{BMI}\left(\mathrm{kg} / \mathrm{m}^{2}\right)$ & $23.2( \pm 3.46)$ \\
\hline \multicolumn{2}{|l|}{ Schooling level (years of medical school) } \\
\hline $1-2$ & 459 (34.0\%) \\
\hline $3-4$ & $491(36.4 \%)$ \\
\hline $5-6$ & $400(29.6 \%)$ \\
\hline QoL personal & $7.86( \pm 1.27)$ \\
\hline QoL medical course & $6.51( \pm 1.56)$ \\
\hline \multicolumn{2}{|l|}{ WHO QOL } \\
\hline Physical health & $65.2( \pm 14.7)$ \\
\hline Psychological & $61.7( \pm 15.7)$ \\
\hline Social relations & $63.6( \pm 19.9)$ \\
\hline Environment & $63.8( \pm 14.1)$ \\
\hline \multicolumn{2}{|l|}{ VERAS-Q } \\
\hline Time management & $37.4( \pm 15.5)$ \\
\hline Psychological & $51( \pm 16.1)$ \\
\hline Physical health & $54.5( \pm 18.3)$ \\
\hline Learning environment & $57.2( \pm 13.1)$ \\
\hline Epworth sleepiness scale & $10.3( \pm 3.9)$ \\
\hline Global PSQI & $6.72( \pm 3.02)$ \\
\hline Becks depression inventory & $9.37( \pm 7)$ \\
\hline Resilience scale (RS-14) & $78.7( \pm 12.4)$ \\
\hline \multicolumn{2}{|l|}{ STAI } \\
\hline State & $43.7( \pm 11.6)$ \\
\hline Trait & $45.5( \pm 11.7)$ \\
\hline \multicolumn{2}{|l|}{ IRMS } \\
\hline Empathy & $26.1( \pm 4.82)$ \\
\hline Emotional & $24.7( \pm 5.04)$ \\
\hline Personal anguish & $19.2( \pm 4.22)$ \\
\hline \multicolumn{2}{|l|}{$\mathrm{MBI}$} \\
\hline Emotional exhaustion & $26.7( \pm 9.8)$ \\
\hline Depersonalization & $8.55( \pm 5.74)$ \\
\hline Reduced personal accomplishment & $33.8( \pm 7.61)$ \\
\hline Global DREEM* score & $119( \pm 27.1)$ \\
\hline
\end{tabular}

$S D$ standard deviation, $B M I$ Body Mass Index, $B D /$ beck depression inventory, PSQI Pittsburgh Sleep Quality Index, STAI state-trait anxiety inventory, IRMS interpersonal reactivity multidimensional scale, MBI Maslach burnout inventory, DREEM Dundee ready education environment measure, RS-14 resilience scale

at median of 67.9 (6.06 vs. $7.19,7.58$ vs. 8.29), VERAS$\mathrm{Q}$ domains including time management scores at median of 36.4 (5.95 vs. $7.15,7.62$ vs. 8.14 ), psychological at median of 50 ( 5.98 vs. $7.07,7.49$ vs. 8.25 ), physical health at median 53.1 ( 5.90 vs. $7.14,7.34$ vs. 8.40 ), and learning environment at median of 57.1 (5.94 vs. 7.12, 7.54 vs. 8.21), State-Trait Anxiety Inventory-State score at median 43 (6.98 vs. 6.02, 8.23 vs. 7.48), State-Trait Anxiety Inventory-Trait score at median 45 (7 vs. 6.01, 8.23 


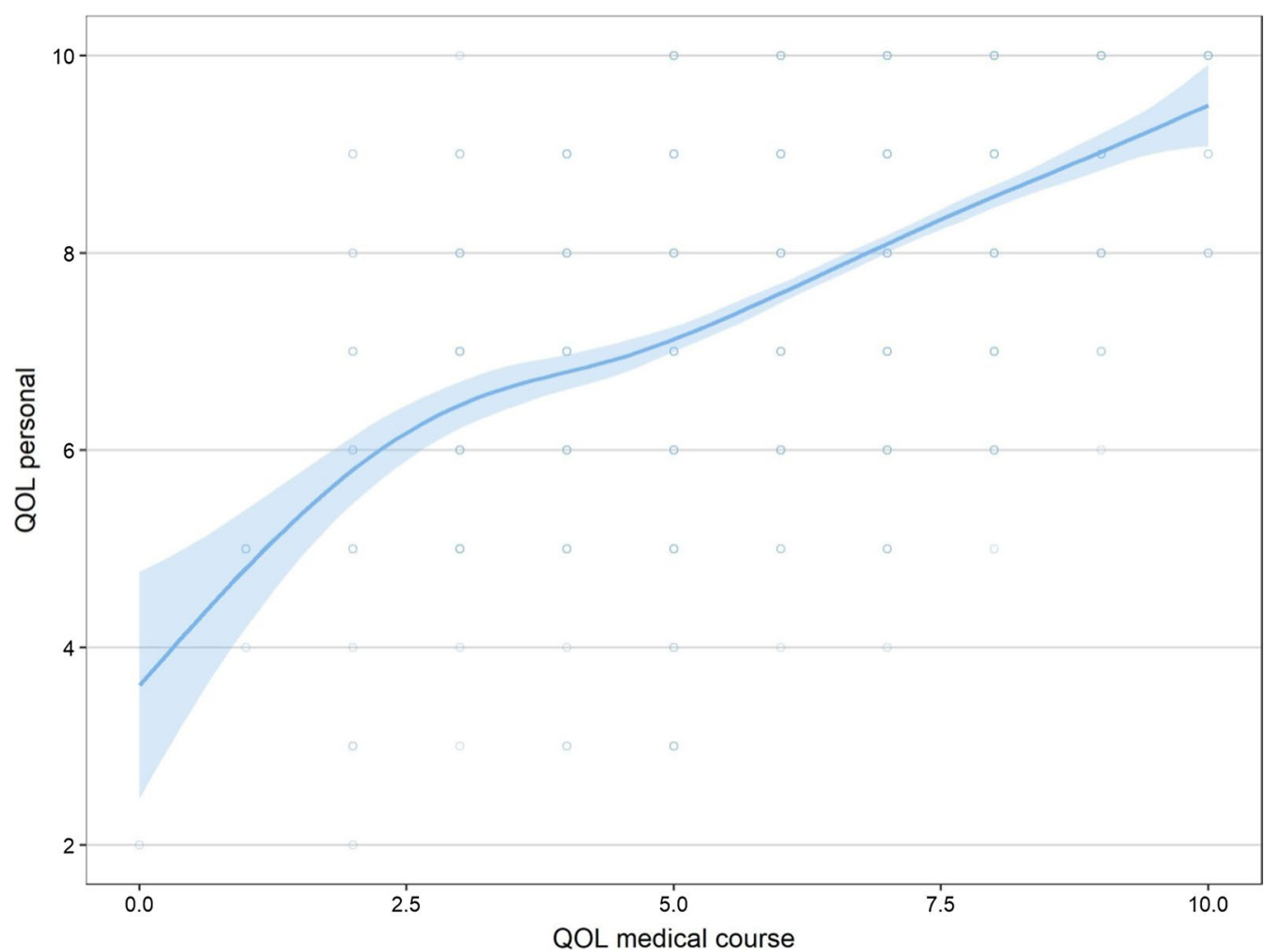

Fig. 1 Association between personal and medical course quality of life. Legend: QOL personal-personal Quality of Life; QOL medical course-Quality of Life related to medical course

vs. 7.49), Interpersonal Reactivity Multidimensional Scale-Personal Anguish domain score at median of 19 ( 6.65 vs. $6.35,8.00$ vs. 7.70 ), Maslach Burnout Inventory domains including emotional exhaustion at median of 27 (7.02 vs. $5.94,8.13$ vs. 7.57$)$, depersonalization with median of 8 (6.78 vs. $6.19,8.01$ vs. 7.69$)$, and personal accomplishment with median of 35 (6.24 vs. 6.84, 7.68 vs. 8.09), Dundee Ready Education Environment Measure global score at median of 120 (6.00 vs. 7.05, 7.63 vs. 8.11), and Resilience Scale score at median of 81 (6.24 vs. 6.82, 7.61 vs. 8.15 ), all demonstrating non-overlapping confidence intervals in relation to their predicted means with a $p$ for trend $<0.001$.

\section{Tree regression model}

We then attempted to validate our results by running a tree regression model (recursive partitioning) including all questionnaires and domain as predictors, identifying the main sequential factors leading to the prediction of medical student's quality of life related (QoL) to the medical course. The model demonstrated that the VERAS-Q-physical health domain was the most important factor predicting QoL, followed by VERASQ-time management, VERAS-Q-learning environment, WHOQOL-BREF-physical health, and Maslach
Burnout Inventory-Emotional exhaustion domain. We found that the students with a VERAS-Q-physical health score $\geq 60.9$ and a VERAS-Q-time management score $\geq 55.7$ presented the best QoL related to the medical course with a score of $8.08(9.63 \%)$, while those with VERAS-Q-physical health score $<60.9$ associated with a VERAS-Q-learning environment score $<56.2$ were associated with the lowest QoLmc $(3.79,2.15 \%)$. Additional combinations of scores were associated with intermediate QoLmc scores as demonstrated in Fig. 2.

When evaluating all predictors of student's personal QoL, the VERAS-Q-physical health domain was the most significant predictor, followed by WHOQOLBREF-psychological health, WHOQOL-BREF-environment, and WHOQOL-BREF-social relationships domains. Students with a VERAS-Q-physical health score $\geq 54.7$ presented the highest personal QoL score of $8.93(8.74 \%)$, whereas the lowest QoLp score (5.57, $1.56 \%$ ) was found among students with a VERASQ-physical health score of $<54.7$ associated with a WHOQOL-psychological health score $<43.8$ and a WHOQOL-social relationships score $<20.9$. Additional combinations of scores were associated with intermediate personal QoL scores as demonstrated in Fig. 3. 
Table 2 Predictors of quality of life of medical students adjusted for age and BMI

\begin{tabular}{|c|c|c|c|c|}
\hline Predictor (median) & $\begin{array}{l}\text { QOL medical course } \\
\text { Mean }(\mathrm{Cl})\end{array}$ & $p$ for trend & $\begin{array}{l}\text { QOL personal } \\
\text { Mean }(\mathrm{Cl})\end{array}$ & $p$ for trend \\
\hline Beck depression inventory & & $p<0.001$ & & $p<0.001$ \\
\hline$\leq 8$ & $6.96(6.85,7.06)$ & & $8.17(8.08,8.26)$ & \\
\hline$>8$ & $6.02(5.90,6.13)$ & & $7.53(7.43,7.62)$ & \\
\hline Global PSQI & & $p<0.001$ & & $p<0.001$ \\
\hline$\leq 6$ & $6.93(6.82,7.04)$ & & $8.12(8.02,8.21)$ & \\
\hline$>6$ & $6.07(5.95,6.18)$ & & $7.60(7.50,7.69)$ & \\
\hline Epworth sleepiness scale & & $p<0.001$ & & $p<0.001$ \\
\hline$\leq 10$ & $6.84(6.72,6.95)$ & & $7.98(7.89,8.08)$ & \\
\hline$>10$ & $6.14(6.02,6.26)$ & & $7.73(7.63,7.83)$ & \\
\hline WHO QOL_environment & & $p<0.001$ & & $p<0.001$ \\
\hline$\leq 65.6$ & $6.04(5.94,6.14)$ & & $7.49(7.41,7.57)$ & \\
\hline$>65.6$ & $7.14(7.02,7.26)$ & & $8.36(8.27,8.46)$ & \\
\hline WHO QOL_-social relations & & $p<0.001$ & & $p<0.001$ \\
\hline$\leq 66.7$ & $6.22(6.11,6.32)$ & & $7.61(7.52,7.7)$ & \\
\hline$>66.7$ & $6.94(6.81,7.06)$ & & $8.23(8.13,8.33)$ & \\
\hline WHO QOL_-psychological & & $p<0.001$ & & $p<0.001$ \\
\hline$\leq 62.5$ & $5.98(5.87,6.08)$ & & $7.48(7.4,7.57)$ & \\
\hline$>62.5$ & $7.13(7.01,7.24)$ & & $8.30(8.21,8.40)$ & \\
\hline WHO QOL_physical health & & $p<0.001$ & & $p<0.001$ \\
\hline$\leq 67.9$ & $6.06(5.96,6.16)$ & & $7.58(7.5,7.66)$ & \\
\hline$>67.9$ & $7.19(7.07,7.31)$ & & $8.29(8.19,8.39)$ & \\
\hline STAI_state & & $p<0.001$ & & $p<0.001$ \\
\hline$\leq 43$ & $6.98(6.87,7.09)$ & & $8.23(8.14,8.32)$ & \\
\hline$>43$ & $6.02(5.91,6.14)$ & & $7.48(7.39,7.57)$ & \\
\hline STAI_trait & & $p<0.001$ & & $p<0.001$ \\
\hline$\leq 45$ & $7.00(6.89,7.11)$ & & $8.23(8.14,8.32)$ & \\
\hline$>45$ & $6.01(5.9,6.13)$ & & $7.49(7.39,7.58)$ & \\
\hline EMRI/IRMS_empathy & & $p=0.361$ & & $p=0.972$ \\
\hline$\leq 26$ & $6.55(6.43,6.67)$ & & $7.87(7.77,7.96)$ & \\
\hline$>26$ & $6.47(6.35,6.59)$ & & $7.86(7.77,7.96)$ & \\
\hline EMRI/IRMS—emotional & & $p=0.298$ & & $p=0.887$ \\
\hline$\leq 25$ & $6.47(6.36,6.59)$ & & $7.87(7.78,7.96)$ & \\
\hline$>25$ & $6.56(6.44,6.68)$ & & $7.86(7.76,7.96)$ & \\
\hline EMRI/IRMS—personal anguish & & $p<0.001$ & & $p<0.001$ \\
\hline$\leq 19$ & $6.65(6.54,6.76)$ & & $8.00(7.91,8.09)$ & \\
\hline$>19$ & $6.35(6.22,6.47)$ & & $7.70(7.60,7.80)$ & \\
\hline MBI_emotional exhaustion & & $p<0.001$ & & $p<0.001$ \\
\hline$\leq 27$ & $7.02(6.92,7.13)$ & & $8.13(8.04,8.22)$ & \\
\hline$>27$ & $5.94(5.83,6.05)$ & & $7.57(7.47,7.66)$ & \\
\hline $\mathrm{MBI}$ —depersonalization & & $p<0.001$ & & $p<0.001$ \\
\hline$\leq 8$ & $6.78(6.67,6.9)$ & & $8.01(7.92,8.11)$ & \\
\hline$>8$ & $6.19(6.07,6.31)$ & & $7.69(7.59,7.79)$ & \\
\hline $\mathrm{MBI}$ —reduced personal accomplishment & & $p<0.001$ & & $p<0.001$ \\
\hline$\leq 35$ & $6.24(6.12,6.35)$ & & $7.68(7.58,7.77)$ & \\
\hline$>35$ & $6.84(6.72,6.96)$ & & $8.09(7.99,8.19)$ & \\
\hline VERAS-Q_-time management & & $p<0.001$ & & $p<0.001$ \\
\hline$\leq 36.4$ & $5.95(5.85,6.06)$ & & $7.62(7.53,7.71)$ & \\
\hline$>36.4$ & $7.15(7.04,7.26)$ & & $8.14(8.04,8.24)$ & \\
\hline
\end{tabular}


Table 2 (continued)

\begin{tabular}{|c|c|c|c|c|}
\hline Predictor (median) & $\begin{array}{l}\text { QOL medical course } \\
\text { Mean }(\mathrm{Cl})\end{array}$ & $p$ for trend & $\begin{array}{l}\text { QOL personal } \\
\text { Mean }(\mathrm{Cl})\end{array}$ & $p$ for trend \\
\hline VERAS-Q_psychological & & $p<0.001$ & & $p<0.001$ \\
\hline$\leq 50$ & $5.98(5.87,6.09)$ & & $7.49(7.4,7.58)$ & \\
\hline$>50$ & $7.07(6.96,7.18)$ & & $8.25(8.16,8.35)$ & \\
\hline VERAS-Q_-physical health & & $p<0.001$ & & $p<0.001$ \\
\hline$\leq 53.1$ & $5.90(5.79,6.01)$ & & $7.34(7.25,7.43)$ & \\
\hline$>53.1$ & $7.14(7.03,7.25)$ & & $8.4(8.32,8.49)$ & \\
\hline VERAS-Q_learning environment & & $p<0.001$ & & $p<0.001$ \\
\hline$\leq 57.1$ & $5.94(5.83,6.05)$ & & $7.54(7.45,7.63)$ & \\
\hline$>57.1$ & $7.12(7.01,7.23)$ & & $8.21(8.11,8.30)$ & \\
\hline Global DREEM score & & $p<0.001$ & & $p<0.001$ \\
\hline$\leq 120$ & $6.00(5.89,6.11)$ & & $7.63(7.53,7.72)$ & \\
\hline$>120$ & $7.05(6.93,7.16)$ & & $8.11(8.02,8.21)$ & \\
\hline RS-14 score & & $p<0.001$ & & $p<0.001$ \\
\hline$\leq 81$ & $6.24(6.13,6.35)$ & & $7.61(7.52,7.7)$ & \\
\hline$>81$ & $6.82(6.7,6.94)$ & & $8.15(8.05,8.25)$ & \\
\hline
\end{tabular}

CI confidence interval, PSQI Pittsburgh Sleep Quality Index, STAI state-trait anxiety inventory, IRMS Interpersonal Reactivity Multidimensional Scale, MBI Maslach burnout inventory, DREEM Dundee ready education environment measure, $R S-14$ resilience scale

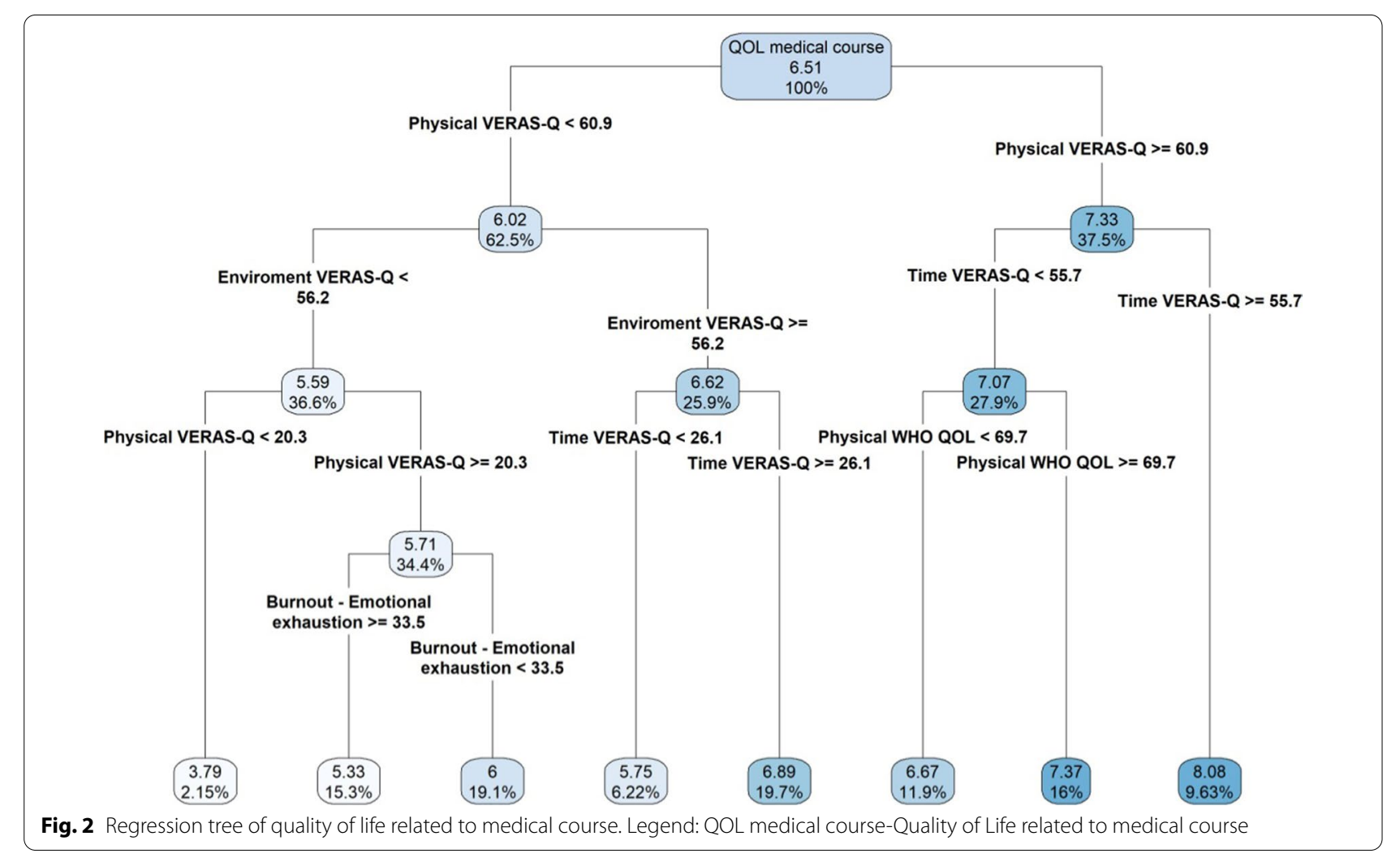




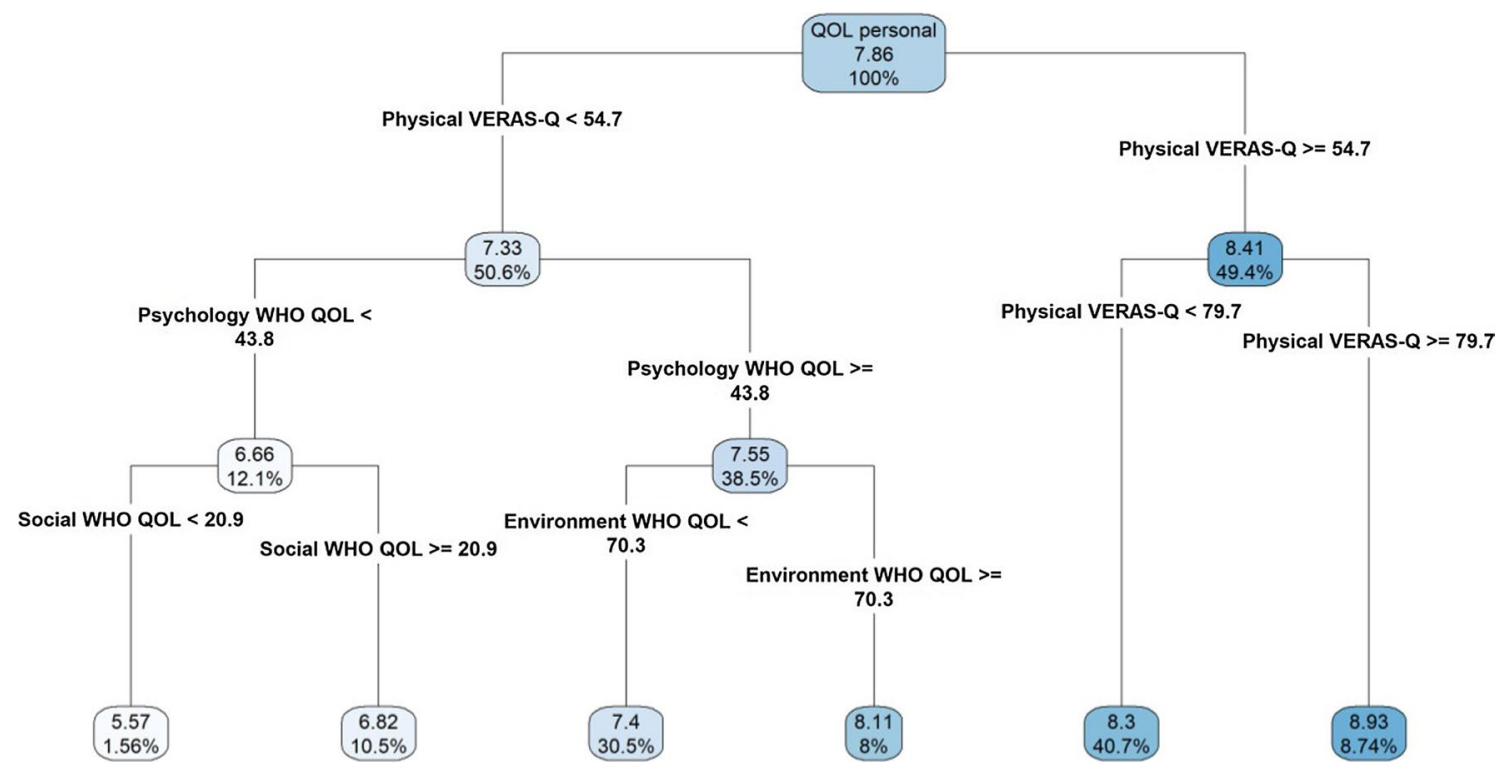

Fig. 3 Regression tree of personal quality of life. Legend: QOL personal-personal Quality of Life

\section{Discussion}

In this study, we chose to explore the characteristics of the medical student's Quality of Life in an innovative and global way. We did so by seeking mainly protective factors of the educational environment and the medical training program, which can be an effective strategy to reverse stigma associated with the mental health of these students. In addition, by expanding knowledge about associated factors to mental health protection for medical students, the data can provide a substrate for the continuous improvement of medical school curricula.

The general sample of this study showed a discreet predominance of females (52.9\%), reflecting a current international and national trend of "feminization" of medicine [70-72]. In Brazil, since 2005, there are more women in medical school than men and in 2011-2012, when this study was carried out, females represented $54.3 \%$ of the medical students [70]. In addition, the sample consists of young people with an average age of 22.8 years.

Analyzing the outcomes: personal and medical course Quality of Life (QoLp and QoLmc respectively), we noticed that there is a positive and concordant correlation between them. Medical students, however, attributed worse scores to QoLmc. In the data collection, these two questions were triggered consecutively, and their answers were scored from 0 to 10 , making clear the minimum and maximum values. Therefore, it looks like that it was intentional on the part of the students to reinforce this difference, giving indications that the teaching environment and the curricular requirements directly affect their perception of Quality of Life and, thus, expressing their discontent. Several authors have already pointed out the dissatisfaction of medical students with the course and the direct negative influence on their Quality of Life, physical and mental health $[1,2,73,74]$.

In the general analysis of the questionnaires assessing Quality of Life (WHOQOL-BREF and VERAS-Q) the most visually significant result was the mean of the VERAS-Q time management domain (37.4), which is much lower than in the other domains of the same questionnaire (from 51 to 57). This was repeated in the analysis made by multiple linear regression. The univariate inferential analysis showed a negative correlation between depressive symptoms, daytime sleepiness and sleep disorder with the Quality of Life outcomes of this study (QoL personal and in medical course). When interpreting the results of multiple linear regression based on the questionnaire cuts, we identified that any degree of depressive symptom, mild to severe, is associated with worse QoLp and QoLmc (IDB > 8). Likewise, any degree of daytime sleepiness and poor sleep quality is associated with worse QoL personal and in medical course (Epworth $>10$ and PSQI $>6$ ). We understand that depressive symptoms, poor sleep quality and daytime sleepiness have a negative impact and are risk factors for a worse Quality of Life.

This result presents clinical and physiological corroboration, in addition to several other studies with similar conclusions: studies attribute to the medical course a negative effect on the mental health of medical students, resulting in a high prevalence of depression, anxiety, stress and sleep disorders [18-20,37, 75-77]. In addition, 
sleep disorders lead to mental, psychological and physical morbidities [78-80].

Students with moderately high and high resilience had better perceptions of personal and medical course QoL (RS-14>81), suggesting it was a protective factor. This result is in line with other studies that demonstrate a dose-effect relationship between resilience, perception of the teaching environment and quality of life for medical students [35, 42, 81-83]. Accordingly, there is a current international movement for valuing this characteristic that has even become part of the new essential competences for the newcomer by the AAMC (Association of American Medical Colleges) [83].

Likewise, a better perception of the teaching environment (Excellent and More positive than negative in DREEM questionnaire) was also associated with better Quality of Life, as in other publications, but it is difficult to verify the causal relationship between them [40].

Regarding the findings obtained by the tree regression, our first conclusion is that VERAS-Q questionnaire developed for evaluation Quality of Life in medical students had greater power to discriminate students with better and worse quality of life in the course of medicine. Another interesting evidence was the secondary role of the results of the other questionnaires (MBI, BDI, IDATE, RS-14, EMRI, Epworth, PSQI and DREEM) and, therefore, did not enter the tree regression. In the literature, we realized that most studies focus on the assessment of students' physical, psychological and mental health through these questionnaires.

The first tree node in both personal and in the course QoL tree regression, was the Physical domain of VERASQ. This domain assesses self-care, self-perception of health, sleep, leisure, physical activity and appearance. That is, aspects that may reflect characteristics raised as risk and protective factors (depressive and anxious symptoms, burnout, sleep disorders and physical activity) and a global assessment (that mirrors this information indirectly and its physical impact) played a predominant role. This may reflect the multidimensional and subjective definition of Quality of Life and that, according to WHO, health and well-being are not just the absence of disease $[84,85]$

When we focus on the personal Quality of Life (QoLp), the group with the best perception of physical health (score in the Physical domain of VERAS-Q > 54.7) had the best scores in the QoLp, and those with scores greater than 79.7 had an average of QoLp at 8.93. Remembering that the value associated with better or worse Qolp by multiple linear regression was 53.1 . Thus, we realized that our two analyzes found similar results, and therefore, better perception of health and self-care, in addition to sleep, leisure, physical activity and appearance, seems to be protective factors.

Leaving to the other branch of the tree towards students with worse QoLp (average of 5.57), they score less than 54.7 in the Physical domain of VERAS-Q, less than 43.8 in the Psychological domain of WHOQOL-BREF, and less than 20.9 in the WHOQOL-BREF Social Relations domain. The Psychological domain of WHOQOLBREF addresses Quality of Life in relation to positive thoughts, thinking, learning, memory, concentration, self-esteem, body image, negative feelings, spirituality and personal beliefs; and the WHOQOL-BREF Social Relations domain evaluates interpersonal and social relationships, support networks and sexual activity. The fact that the sequence of these domains (Physical of VERAS-Q, Psychological and Social Relations of WHOQOL-BREF) is more significant to characterize students with worse grades of QoLp (to the detriment of the other questionnaires), demonstrates the reliability of the WHOQOL-BREF questionnaire and confirms the multidimensionality of the Quality of Life concept [86].

The Quality of Life tree regression in the medical course (QoLmc) also begins in the Physical domain of VERAS-Q, but at a higher value than in the QoLp regression tree $(60.9 \times 54.7)$. This difference can be explained by the academic requirements and therefore, lower degrees of worse perception of physical health already have an impact on satisfaction with the course.

In the branch of students with better QoLmc, the time management domain of VERAS-Q above 55.7 appears as the second determinant. This value being well above the average found in the sample and the dividing value in the multiple linear regression (37.4 and 36.4). In this domain the questions address the management of the student's time, free time and whether he can dedicate himself to other activities besides the course.

Moving to the other extreme, the worst QoLmc scores (mean of 3.79) are associated with VERAS-Q Physical domain scores $(<20.3)$ and VERAS-Q Teaching Environment scores less than 56.2, a value similar to that found in multiple linear regression (57). This domain covers the teaching environment, the organization of the course, relations with colleagues, teachers and the educational institution. Therefore, students with the worst perceptions of physical health and self-care, as well as the worst perception of the teaching environment, make up the group of worst perceptions of Quality of Life in the medical course.

This study has important strengths. We randomly selected our sample to reduce response bias and included 22 medical schools, representing every region of Brazil, allowing us to generalize our results to medical students throughout the country. However, it has some 
limitations. The main limitation is its cross-sectional design that prevents us from making causal inferences. Another potential limitation is that some instruments had a Cronbach's alpha $<0.70$. In addition, we cannot directly generalize our results to other countries.

\section{Conclusion}

Assessing the medical student's Quality of Life globally, the specific symptoms of psychosocial suffering and mental disorders (such as depression, anxiety, burnout and sleep) individually have less association with the final outcome than a general perception of students regarding their physical and mental health, both for better and for worse Quality of Life. A questionnaire specifically developed for evaluation Quality of Life in medical students had greater power to discriminate students with better and worse quality of life in the course of medicine.

Another striking result of our analyzes is the protective role of the time management variable. Time management is considered the key to success in several professions and is also necessary for the balance of personal and professional life. Thus, we understand that educational institutions, in addition to revising their curricula to include free time for study and leisure, should introduce activities for students to develop time management skills.

\section{Supplementary Information}

The online version contains supplementary material available at https://doi. org/10.1186/s40359-021-00534-5.

Additional file 1: VERAS-Q questionnaire.

\section{Abbreviations}

AAMC: Association of American Medical Colleges; BDI: Beck depression inventory; BMI: Body Mass Index; DREEM: Dundee ready education environment measure; SD:: Standard deviation; ESS: Epworth sleepiness scale; IRMS: Interpersonal reactivity multidimensional scale; MBI: Maslach burnout inventory; MLRM: Multiple linear regression models; PSQI: Pittsburgh sleep quality index; QoL: Quality of life; QoLp: Personal quality of life; QoLmc: Quality of life related to medical course activities; RS-14: Resilience scale; RTM: Regression trees model; SPSS: Statistical product and service solutions; STAI: State-trait anxiety inventory; STROBE: Strengthening the reporting of observational studies in epidemiology; VERAS: An acronym that means life of students and residents of health professions; VERAS-Q: An acronym that means life of students and residents of health professions questionnaire; WHO: World Health Organization; WHOQOL-BREF: The World Health Organization Quality of Life Assessment abbreviated version.

\section{Acknowledgements}

The authors thank Ricardo Pietrobon, from Duke University Medical Center for his contribution in data analysis.

\section{Authors' contributions}

Conceived and designed the experiments: FBM, PT, MAM. Performed the experiments: FBM, PT, MAM. Analyzed the data: AQCM, RK, PT, MAM. Wrote the paper: AQCM, RK, PT, MAM. Reviewed the manuscript: FBM, AQCM, RK, PT, MAM. All authors read and approved the final manuscript.

\section{Funding}

This study was supported by the following Brazilian scientific agencies: CAPES (Coordination for the Improvement of Higher Education Personnel-http:// www.capes.gov.br) and CNPq (Brazilian National Council for Scientific and Technological Development-http://www.cnpq.br). The funders had no role in the study design, data collection and analysis, decision to publish or preparation of the manuscript.

\section{Availability of data and materials}

The datasets used and/or analyzed during the current study are available from the corresponding author on reasonable request.

\section{Ethics approval and consent to participate}

The research protocol was approved by the Ethics Committee of the School of Medicine of the University of São Paulo. The first page of the survey in the VERAS platform was the written informed consent, the student could only continue if he/she read and agreed to participate in the study. All the informed consents were written and digitally saved.

\section{Consent for publication}

Not applicable.

\section{Competing interests}

The authors declare that they have no competing interests.

\section{Author details}

${ }^{1}$ Centro de Desenvolvimento de Educação Médica, Faculdade de Medicina da Universidade de Sao Paulo, Av. Dr. Arnaldo 455 sala 1210, Sao Paulo, SP 01246-903, Brazil. ${ }^{2}$ Departamento de Clínica Médica, Faculdade de Medicina da Universidade de São Paulo, São Paulo, Brazil. ${ }^{3}$ Hospital Universitário da Universidade Federal de São Carlos, São Carlos, Brazil. ${ }^{4}$ Pontifícia Universidade Católica do Paraná, Curitiba, Brazil.

Received: 16 July 2020 Accepted: 9 February 2021

Published online: 25 February 2021

\section{References}

1. Wolf TM. Stress, coping and health: enhancing well-being during medical school. Med Educ. 1994;28:8-17. https://doi. org/10.1111/j.1365-2923.1994.tb02679.x.

2. Tempski P, Bellodi PL, Paro HB, et al. What do medical students think about their quality of life? A qualitative study. BMC Med Educ. 2012. https ://doi.org/10.1186/1472-6920-12-106.

3. Voltmer E, Kötter T, Spahn C. Perceived medical school stress and the development of behavior and experience patterns in German medical students. Med Teach. 2012;34:840-7. https://doi.org/10.3109/01421 59X.2012.706339.

4. Dyrbye LN, Harper W, Durning SJ, et al. Patterns of distress in US medical students. Med Teach. 2011;33:834-9. https://doi.org/10.3109/01421 59X.2010.531158.

5. Ball S, Bax A. Self-care in medical education: effectiveness of health-habits interventions for first-year medical students. Acad Med. 2002;77:911-7. https://doi.org/10.1097/00001888-200209000-00023.

6. Nogueira-Martins LA. Saúde mental dos profissionais de saúde. Rev Bras Med do Trab. 2003;1:59-71.

7. Guthrie E, Black D, Bagalkote $H$, et al. Psychological stress and burnout in medical students: a five-year prospective longitudinal study. J R Soc Med. 1998;91:237-43. https://doi.org/10.1177/014107689809100502.

8. Messina G, Quercioli C, Troiano G, et al. Italian medical students quality of life: years 2005-2015. Ann Ig. 2016;28:245-51. https://doi.org/10.7416/ ai.2016.2103.

9. Pagnin D, De Queiroz V. Comparison of quality of life between medical students and young general populations. Educ Heal Chang Learn Pract. 2015;28:209-12. https://doi.org/10.4103/1357-6283.178599.

10. Singh R. Pilot study to assess the quality of life, sleepiness and mood disorders among first year undergraduate students of medical, engineering and arts. J Clin Diagn Res. 2016. https://doi.org/10.7860/ JCDR/2016/19140.7878. 
11. Paro CA, Bittencourt ZZ. Qualidade de vida de graduandos da área da saúde. Rev Bras Educ Méd. 2013;37(3):365-75. https://doi.org/10.1590/ S010055022013000300009.

12. Henning MA, Krägeloh CU, Hawken SJ, et al. The quality of life of medical students studying in New Zealand: a comparison with nonmedical students and a general population reference group. Teach Learn Med. 2012;24:334-40. https://doi.org/10.1080/10401334.2012.715261.

13. Dyrbye LN, Thomas MR, Power DV, et al. Burnout and serious thoughts of dropping out of medical school: a multi-institutional study. Acad Med. 2010;85:94-102. https://doi.org/10.1097/ACM.0b013e3181c46aad.

14. Dyrbye LN, Thomas MR, Massie FS, et al. Burnout and suicidal ideation among US Medical Students. Ann Intern Med. 2008;149:334. https://doi. org/10.7326/0003-4819-149-5-200809020-00008.

15. Frajerman A, Morvan $Y$, Krebs M-O, et al. Burnout in medical students before residency: a systematic review and meta-analysis. Eur Psychiatry. 2019:55:36-42. https://doi.org/10.1016/j.eurpsy.2018.08.006.

16. van Venrooij LT, Barnhoorn PC, Giltay EJ, et al. Burnout, depression and anxiety in preclinical medical students: a cross-sectional survey. Int J Adolesc Med Health. 2015. https://doi.org/10.1515/ijamh-2015-0077.

17. Fiorotti KP, Rossoni RR, Borges LH, et al. Transtornos mentais comuns entre os estudantes do curso de medicina: prevalência e fatores associados. J Bras Psiquiatr. 2010;59:17-23. https://doi.org/10.1590/S0047-20852 010000100003

18. Rotenstein LS, Ramos MA, Torre M, et al. Prevalence of depression, depressive symptoms, and suicidal ideation among medical students. JAMA. 2016;316:2214. https://doi.org/10.1001/jama.2016.17324

19. Puthran R, Zhang MWB, Tam WW, et al. Prevalence of depression amongst medical students: a meta-analysis. Med Educ. 2016;50:456-68. https://doi. org/10.1111/medu.12962.

20. Pacheco JPG, Giacomin HT, Tam WW, et al. Mental health problems among medical students in Brazil: a systematic review and meta-analysis. Rev Bras Psiquiatria. 2017;39:369-78. https://doi. org/10.1590/1516-4446-2017-2223.

21. Dyrbye LN, West CP, Satele D, et al. Burnout among US medical students, residents, and early career physicians relative to the general US population. Acad Med. 2014;89:443-51. https://doi.org/10.1097/ACM.00000 00000000134

22. Dyrbye LN, Thomas MR, Harper W, et al. The learning environment and medical student burnout: a multicentre study. Med Educ. 2009;43:27482. https://doi.org/10.1111/j.1365-2923.2008.03282.x.

23. Jackson ER, Shanafelt TD, Hasan O, et al. Burnout and alcohol abuse/ dependence among US medical students. Acad Med. 2016;91:1251-6. https://doi.org/10.1097/ACM.0000000000001138.

24. Colby L, Mareka M, Pillay S, Sallie F, van Staden C, du Plessis ED, Joubert G. The association between the levels of burnout and quality of life among fourth-year medical students at the University of the Free State. S Afr J Psychiatr. 2018;25(24):1101. https://doi.org/10.4102/sajpsychiatry.v24i0 1101.

25. Boni RADS, Paiva CE, de Oliveira MA, Lucchetti G, Fregnani JHTG, Paiva BSR. Burnout among medical students during the first years of undergraduate school: prevalence and associated factors. PLoS ONE. 2018;13(3):e0191746. https://doi.org/10.1371/journal.pone.0191746.

26. Moutinho ILD, Lucchetti ALG, Ezequiel ODS, Lucchetti G. Mental health and quality of life of Brazilian medical students: Incidence, prevalence, and associated factors within two years of follow-up. Psychiatry Res. 2019;274:306-12. https://doi.org/10.1016/j.psychres.2019.02.041.

27. Borges GBM, Eidt I, Zilli LN, Michels AMMP, Diaz AP. Defense mechanisms and quality of life of medical students according to graduation phase. Trends Psychiatry Psychother. 2020;42(1):74-81. https://doi. org/10.1590/2237-6089-2019-0022.

28. Shareef MA, AIAmodi AA, Al-Khateeb AA, et al. The interplay between academic performance and quality of life among preclinical students. BMC Med Educ. 2015;15:193. https://doi.org/10.1186/s12909-015-0476-1.

29. Henning MA, Krägeloh CU, Hawken SJ, et al. Motivation to learn, quality of life and estimated academic achievement: medical students studying in New Zealand. Med Sci Educ. 2011;21:142-50. https://doi.org/10.1007/ BF03341611.

30. Lyndon MP, Henning MA, Alyami H, et al. Burnout, quality of life, motivation, and academic achievement among medical students: A personoriented approach. Perspect Med Educ. 2017;6:108-14. https://doi. org/10.1007/s40037-017-0340-6.
31. Sarwar S, Aleem A, Nadeem MA. Health related quality of life (HRQOL) and its correlation with academic performance of medical students. Pak J Med Sci. 2019;35(1):266-70. https://doi.org/10.12669/pjms.35.1.147.

32. Hattu VK, Sahu PK, Simboo S, Singh A, et al. An exploratory study of quality of life and its relationship with academic performance among students in medical and other health professions. Med Sci (Basel). 2020;8(2):23. https://doi.org/10.3390/medsci8020023.

33. Rogers CR. Toward a more human science of the person. J Human Psychol. 1985;25(4):7-24. https://doi.org/10.1177/0022167885254002.

34. Rogers CR. Carl Rogers on the development of the person-centered approach. Person Centered Rev. 1986;1(3):257-9.

35. Paro HBMS, Morales NMO, Silva CHM, et al. Health-related quality of life of medical students. Med Educ. 2010;44:227-35. https://doi. org/10.1111/j.13652923.2009.03587.x.

36. Paro HBMS, Silveira PSP, Perotta B, et al. Empathy among medical students: is there a relation with quality of life and burnout? PLOS ONE. 2014;9:e94133. https://doi.org/10.1371/journal.pone.0094133.

37. Brenneisen Mayer F, Souza Santos I, Silveira PSP, et al. Factors associated to depression and anxiety in medical students: a multicenter study. BMC Med Educ. 2016;16:1-9. https://doi.org/10.1186/s12909-016-0791-1.

38. Peleias M, Tempski P, Paro HB, et al. Leisure time physical activity and quality of life in medical students: results from a multicentre study. BMJ Open Sport Exerc Med. 2017;3:e000213. https://doi.org/10.1136/bmjse m-2016-000213.

39. Enns SC, Perotta B, Paro HB, et al. Medical students' perception of their educational environment and quality of life: Is there a positive association? Acad Med. 2016:91:409-17. https://doi.org/10.1097/ACM.00000 00000000952.

40. Tempski P, Santos IS, Mayer FB, et al. Relationship among medical student resilience, educational environment and quality of life. PLOS ONE. 2015a;10:e0131535. https://doi.org/10.1371/journal.pone.0131535.

41. von Elm E, Altman DG, Egger M, et al. The strengthening the reporting of observational studies in epidemiology (STROBE) statement: guidelines for reporting observational studies. Prev Med (Baltim). 2007;45:247-51. https ://doi.org/10.1016/j.ijsu.2014.07.013.

42. Tempski P, Santos IS, Mayer FB, et al. Relationship among medical student resilience, educational environment and quality of life. PLOS ONE. $2015 \mathrm{~b}$. https://doi.org/10.1371/journal.pone.0131535.

43. Escolas Médicas, www.escolasmedicas.com.br

44. Huston P. Reporting on surveys: information for authors and peer reviewers. Can Med Assoc J. 1996;154(11):1695-8.

45. The Whogol Group. The World Health Organization quality of life assessment (WHOQOL): development and general psychometric properties. Soc Sci Med. 1998;46:1569-85. https://doi.org/10.1016/s0277 -9536(98)00009-4.

46. Fleck MP, Louzada S, Xavier M, et al. Aplicação da versão em português do instrumento abreviado de avaliação da qualidade de vida 'WHOQOL-bref' Application of the Portuguese version of the abbreviated instrument of quality life WHOQOL-bref. Rev Saude Publica. 2000;34:178-83. https://doi. org/10.1590/S0034-89102000000200012.

47. Tempski P, Perotta B, Pose RA, et al. A questionnaire on the quality of life of medical students. Med Educ. 2009;43:1107-8. https://doi.org/10.111 1/j.1365-2923.2009.03476.x.

48. Johns MW. A new method for measuring daytime sleepiness: the Epworth sleepiness scale. Sleep. 1991;14:540-5. https://doi.org/10.1093/ sleep/14.6.540.

49. Bertolazi AN, Fagondes SC, Hoff LS, et al. Portuguese-language version of the Epworth sleepiness scale: validation for use in Brazil. J Bras Pneumol. 2009;35:877-83. https://doi.org/10.1590/s1806-37132009000900009.

50. Buysse DJ, Reynolds CF, Monk TH, et al. The Pittsburgh Sleep Quality Index: a new instrument for psychiatric practice and research. Psychiatry Res. 1989:28:193-213. https://doi.org/10.1016/0165-1781(89)90047-4.

51. Bertolazi AN, Fagondes SC, Hoff LS, et al. Validation of the Brazilian Portuguese version of the Pittsburgh Sleep Quality Index. Sleep Med. 2011;12:70-5. https://doi.org/10.1016/j.sleep.2010.04.020.

52. Beck AT, et al. An inventory for measuring depression. Arch Gen Psychiatry. 1961;4:561. https://doi.org/10.1001/archpsyc.1961.01710120031004.

53. Gorenstein C, Andrade L. Validation of a Portuguese version of the Beck Depression Inventory and the State-Trait Anxiety Inventory in Brazilian subjects. Braz J Med Biol Res Rev Bras Pesqui Méd Biol. 1996;29:453-7. 
54. Pesce RP, Assis SG, Avanci JQ, et al. Adaptação transcultural, confiabilidade e validade da escala de resiliência. Cross-cultural adaptation, reliability and validity of the resilience scale. Cad Saude Publica. 2005;21:436-48. https://doi.org/10.1590/S0102-311X2005000200010.

55. Wagnild GM, Young HM. Development and psychometric evaluation of the Resilience Scale. J Nurs Meas. 1993;1:165-78.

56. Spielberger C, Gorsuch R, Lushene R, et al. Manual for the state-trait anxiety inventory (form Y1 to Y2); 1983.

57. Spielberger C. State-trait anxiety inventory: a comprehensive bibliography. New York: Consult Psychol Press; 1989.

58. Biaggio AM, Natalício L, Spielberger C. Desenvolvimento da forma experimental em português do Inventário de Ansiedade Traço-Estado (IDATE), de Spielberger. Arq Bras Psicol Apl. 1977;29:31-44.

59. Koller SH, Camino C, Ribeiro J. Adaptação e validação interna de duas escalas de empatia para uso no Brasil. Estud Psicol. 2001;18:43-53. https ://doi.org/10.1590/S0103-166X2001000300004.

60. Davis MH. A mulitdimensional approach to individual differences in empathy. J Pers Soc Psychol. 1983;44:113-26.

61. Maslach C, Jackson SE. The measurement of experienced burnout. J Organ Behav. 1981;2:99-113. https://doi.org/10.1002/job.4030020205.

62. Benevides-Pereira AMT. MBI-Maslach Burnout Inventory e suas adaptações para o Brasil. An da 32a Reun Anu Psicol 2001; 84-85.

63. Roff S, McAleer S, Harden RM, et al. Development and validation of the Dundee Ready Education Environment Measure (DREEM). Med Teach. 1997;19:295-9. https://doi.org/10.3109/01421599709034208.

64. de Oliveira Filho GR, Vieira JE, Schonhorst L. Psychometric properties of the Dundee Ready Educational Environment Measure (DREEM) applied to medical residents. Med Teach. 2005;27:343-7. https://doi. org/10.1080/01421590500046387.

65. Lee PH. Should we adjust for a confounder if empirical and theoretical criteria yield contradictory results? A simulation study. Sci Rep (Internet). 2014;4:6085.

66. Henning MA, Hawken SJ, Krägeloh C, Zhao Y, Doherty I. Asian medical students: quality of life and motivation to learn. Asia Pac Educ Rev. 2011;12:437-45.

67. Kuhn M, Johnson K. Applied predictive modeling. Berlin: Springer; 2013.

68. Rutten-van Mölken MPMH, Van EKA, van Vliet RCJA. Statistical analysis of cost outcomes in a randomized controlled clinical trial. Health Econ. 1994;3:333-45. https://doi.org/10.1002/hec.4730030507.

69. Friedman J, Hastie T, Tibishirani R. The elements of statistical learning. New York: Springer; 2001.

70. Martins M de A, et al. Estudantes de Medicina e Médicos no Brasil: Números Atuais e Projeções. Projeto Avaliaçao das Escolas Médicas Brasileiras. Relatório I. 2013; 104.

71. Dacre J. Are there too many female medical graduates? No BMJ. 2008;336:749-749. https://doi.org/10.1136/bmj.39505.566701.94.

72. McKinstry B. Are there too many female medical graduates? Yes BMJ. 2008;336:748-748. https://doi.org/10.1136/bmj.39505.491065.94.

73. Rezler AG. Attitude changes during medical school: a review of the literature. J Med Educ. 1974;49:1023-30. https://doi.org/10.1097/00001 888-197411000-00001.
74. Parkerson GR, Broadhead WE, Tse CK. The health status and life satisfaction of first-year medical students. Acad Med. 1990;65:586-8. https://doi. org/10.1097/00001888-199009000-00009.

75. McKerrow I, Carney PA, Caretta-Weyer H, Furnari M, Miller JA. Trends in medical students' stress, physical, and emotional health throughout training. Med Educ Online. 2020;25(1):1709278. https://doi.org/10.1080/10872 981.2019.1709278.

76. Alóe F, Pedroso A, Tavares SM. Epworth Sleepiness Scale outcome in 616 brazilian medical students. Arq Neuropsiquiatr. 1997;55:220-6. https:// doi.org/10.1590/s0004-282x1997000200009.

77. Rodrigues RND, Viegas CAA, Abreu e Silva AAA, et al. Daytime sleepiness and academic performance in medical students. Arq Neuropsiquiatr. 2002;60:6-11. https://doi.org/10.1590/s0004-282×2002000100002.

78. Kloster MC, Perotta B, Hauer Junior A, et al. Sonolência diurna e habilidades sociais em estudantes de medicina. Rev Bras Educ Med. 2013:37:103-9. https://doi.org/10.1590/S0100-55022013000100015.

79. Greimel E, Kato Y, Müller-Gartner M, et al. Internal and external resources as determinants of health and quality of life. PLoS ONE. 2016. https://doi. org/10.1371/journal.pone.0153232.

80. Walia HK, Thompson NR, Katzan I, et al. Impact of sleep-disordered breathing treatment on quality of life measures in a large clinic-based Cohort. J Clin Sleep Med. 2017;13:1255-63. https://doi.org/10.5664/ jcsm.6792.

81. Tempski P, Martins MA, Paro HBMS. Teaching and learning resilience: $a$ new agenda in medical education. Med Educ. 2012;46:345-6. https://doi. org/10.1111/j.1365-2923.2011.04207.x.

82. Lin YK, Lin CD, Lin BY, Chen DY. Medical students' resilience: a protective role on stress and quality of life in clerkship. BMC Med Educ. 2019;19(1):473. https://doi.org/10.1186/s12909-019-1912-4.

83. Dyrbye LN, Power DV, Massie FS, et al. Factors associated with resilience to and recovery from burnout: a prospective, multi-institutional study of US medical students. Med Educ. 2010;44:1016-26. https://doi.org/10.111 1/j.1365-2923.2010.03754.x.

84. Koenig TW, Parrish SK, Terregino CA, et al. Core personal competencies important to entering students' success in medical school: What are they and how could they be assessed early in the admission process? Acad Med. 2013;88:603-13. https://doi.org/10.1097/ACM.0b013e31828b3389.

85. The Whogol Group. The World Health Organization quality of life assessment (WHOQOL): Position paper from the World Health Organization. Soc Sci Med. 1995;41:1403-9. https://doi.org/10.1016/02779536(95)00112-k

86. Segre M, Ferraz FC. O conceito de saúde. Rev Saude Publica. 1997;31:53842. https://doi.org/10.1590/S0034-89101997000600016.

\section{Publisher's Note}

Springer Nature remains neutral with regard to jurisdictional claims in published maps and institutional affiliations.

\footnotetext{
Ready to submit your research? Choose BMC and benefit from:

- fast, convenient online submission

- thorough peer review by experienced researchers in your field

- rapid publication on acceptance

- support for research data, including large and complex data types

- gold Open Access which fosters wider collaboration and increased citations

- maximum visibility for your research: over $100 \mathrm{M}$ website views per year
}

At BMC, research is always in progress.

Learn more biomedcentral.com/submissions 